\title{
Relationship between temperament and character personality dimensions among suicide attempters in an Iranian population
}

\section{Ali Reza Shafiee-Kandjani ${ }^{1}$, Shahrokh Amiri2 ${ }^{*}$, Nima Sarihi ${ }^{2}$, Elham Hosseini ${ }^{3}$, Salman Safikhanlou ${ }^{4}$, Mohsen Jafarzadeh-Ghareziaaddin ${ }^{4}$}

'Road Traffic Injury Research Center, Faculty of Medicine, Tabriz University of Medical Sciences, Tabriz, Iran ${ }^{2}$ Research Center of Psychiatry and Behavioral Sciences, Tabriz University of Medical Sciences, Tabriz, Iran ${ }^{3}$ Department of Internal Medicine, Islamic Azad University, Tabriz Branch, Tabriz, Iran

${ }^{4}$ Clinical Psychologist, Tabriz University of Medical Sciences, Tabriz, Iran

\author{
Received: 16 November 2019 \\ Accepted: 16 December 2019 \\ Published online: 24 December \\ 2019 \\ *Corresponding author: Shahrokh \\ Amiri, Department of Psychiatry, \\ Razi Mental Hospital, El Goli \\ Boulevard, PO Box: 5456, Tabriz, Iran. \\ Tel/Fax: +98 4133803351 \\ Email: sh_amiri1348@yahoo.com \\ Competing interests: None. \\ Funding information: Research \\ Center of Psychiatry and Behavioral \\ Sciences. \\ Citation: Shafiee-Kandjani AR, Amiri \\ S, Sarihi N, Hosseini E, Safikhanlou \\ $\mathrm{S}$, Jafarzadeh-Ghareziaaddin M. \\ Relationship between temperament \\ and character personality \\ dimensions among suicide \\ attempters in an Iranian population. \\ Journal of Emergency Practice \\ and Trauma 2020; 6(1): 33-37. doi \\ $10.15171 /$ jept.2019.26
}

\begin{abstract}
Objective: Two temperamental components that are mostly associated with suicide are high novelty seeking (NS) and high harm avoidance (HA). This study aimed to evaluate the temperament and character personality dimensions of self-poisoning in suicidal attempters in an Iranian population.

Methods: A descriptive-analytic study was conducted with random sampling in which 77 self-poisoning patients and equal normal counterparts were selected. Cloninger's Temperament and Character Inventory (TCl) and clinical interview were used as study procedures. Data were analyzed by SPSS software version 18 using chi-square, MannWhitney $U$ and regression. $P$ values $<0.05$ were considered statistically significant.

Results: Findings showed that people attempting suicide were significantly different from general population in terms of character and temperament. NS and HA yielded high scores in the suicide group, while reward dependence (RD), self-directedness (SD), cooperativeness (CO) and self-transcendence (ST) variables revealed significantly higher scores in the healthy group. No significant difference was observed among suicide attempters in terms of gender.

Conclusion: The results confirm the difference between non-suicidal individuals and suicide attempters in terms of character and temperament in a way that suicidal patients have high harm-avoidance and introversion. In addition, the history of attempts and early alcohol consumption might be considered as suicide re-attempt predictors.

Keywords: Character, Temperament, Suicide, Personality
\end{abstract}

\section{Introduction}

Suicide is a leading cause of death among adolescents worldwide, albeit suicide attempts occur 10-20 times higher (1). Suicide rates in Iran are lower than western countries. Meanwhile, Iran has a higher suicide rate in the Middle East which has been estimated to be 4.9 per 100000 general population (2). Suicide attempt is considered as a psychiatric emergency, but a minority of patients with psychiatric disorders commit suicide (3).

Psychiatric disorders have a pivotal role in causation of suicide that may also be determined by personality traits (4). Several studies have reported an association between personality traits and suicidal behavior. Therefore, some suicide attempts may occur based on underlying personality difficulties (5). Personality is a unique characteristic which discriminates a person from other individuals through motivation, feelings, thoughts and behavior (6).

Researchers have found that committing suicide among women is three times higher than men; they have introduced "gender" as a risk factor for committing suicide. This may be due to the fact that women experience stressful situations, mostly as uncontrollable conditions (7).

In recent decades personality has been characterized by using various models. Cloninger's model of personality, which has been established based on psychobiological theory of personality consists of four temperament dimensions as novelty seeking (NS), harm avoidance (HA), reward dependence $(\mathrm{RD})$ and persistence $(\mathrm{P})$ and 
three characters dimensions including self-directedness (SD), cooperativeness (CO) and self-transcendence (ST). Temperament which is defined as "the automatic associative response to emotional stimuli that determine habits and moods", is considered to be moderately stable through lifespan. On the other hand, character refers to "the self-aware concept that influence our voluntary intentions and attitude", and it is pervasive as the individual's insight matures as their experiences during lifespan (8).

It is a conceivable fact that most of suicide attempters may have maladaptive coping strategies when they experience stressful situations in an uncontrollable manner. Effective coping skills can increase self-control or self-direction and hence prevent suicide attempt. According to a study, patients with suicide attempts use emotion-focused coping strategies much more than problem-focused ones. Women's responses differ from men in this regard because of using less effective strategies (9).

They have reported that most people attempting suicide had low-level education and $79.7 \%$ of suicide attempters had at least one maladaptive personality difficulty. The most common maladaptive personality profiles among suicidal attempters were depressive personality disorder and histrionic personality disorder, equal to $40.7 \%$ and $32.2 \%$, respectively. Among clinical syndromes, the most common syndrome was clinical anxiety (23.7\%), and major depression (23.7\%) (9).

According to a study, novelty-seeking has a significant predictor value because of its meaningful high and low scores in suicidal patients and in patients without suicidal attempts, respectively. They also found that low scores in the Self-directedness is also a potent predictor of suicidal attempts (10).

So far, two temperamental components that are more closely associated with suicide are high novelty seeking (NS) and high harm-avoidance (HA), and other less relevant personality components include low reward dependence (RD), self-directedness (SD) and cooperativeness (CO) as well as high self-transcendence (ST) $(11,12)$.

All of these points not only demand special attention for proper planning in preventing suicide, but raises the necessity of a comprehensive information system for an accurate recording of suicidal cases in Iran as well. For this reason, the authors focused on temperament and character dimensions in patients with self-poisoning suicide attempts at Sina hospital of Tabriz, Iran.

\section{Methods}

The target age group was 18 - to 65 -year-old people who referred to specialized Sina hospital of Tabriz, with a diagnosis of self-poisoning from March 2016 to March 2017.

The individuals in the control group with the same age and sex were selected randomly from non-suicidal outpatients who referred to internal clinics of the same hospital. Also, the people in the control group were clinically interviewed by the examiner and recruited if they lacked previous and current psychiatric diagnosis. Informed consent was granted from individuals.

The sample size was calculated with 0.05 alpha level, power of $80 \%$, the effect size of 0.50 with the G-Power 3.1.2 Software and based on the study of Arkar (10) in Turkey. Therefore, 77 people were selected for each group considering the 20 percent drop-out rate.

Inclusion criteria were suicidal attempts, lack of intellectual disability, ability to read and write, age range of 18 to 65 years, and the intentional attempt for drug poisoning. We excluded patients who were unwilling to participate in the study, having a delirium or dementia, a history of psychotic disorder, substance and alcohol use disorder. In order to collect data we used Cloninger's Temperament and Character Inventory (TCI) and General Health Questionnaire (GHQ).

TCI was developed by Cloninger based on the bio-social model of personality, measuring the temperament in four dimensions of NS, HA, RD and perseverance $(\mathrm{P})$, and character in its three dimensions: SD, CO and ST. The present short version of the test contains 125 questions. It has got a good validity and reliability in Persian language (13).

The General Health Questionnaire (GHQ) was developed by Goldberg and Hiller in 1972 and it is one of the most well-known screening tools in the studies related to mental health. In addition to extracting the total score of the individual mental health, this questionnaire also consists of four subscales of physical symptoms, anxiety, social function disorder, and depression. The test scoring is based on a Likert scale. Its reliability has been confirmed in different cultures. In Iran, the internal consistency of this questionnaire for the sub-scales was $0.85,0.87$, 0.79 , and 0.91 , respectively, based on Cronbach's alpha coefficient (14).

The obtained data were analyzed through SPSS software version 18. We used descriptive and inferential statistics (chi-square, Mann-Whitney $U$ and Regression), and $P$ values $<0.05$ were considered statistically significant.

\section{Results}

Table 1 shows all demographic data. Table 2 shows the statistics on the type and amount of drugs used for committing suicide in the suicide group.

The mean age among all participants was $32.90 \pm 12.38$ years, which in the suicide group it was $32.04 \pm 11.65$ years, and in the normal group it was $33.74 \pm 13.11$. According to the results of the independent $t$ test ( $\mathrm{F}=$ $1.03, \mathrm{t}=0.85, \mathrm{df}=149.91, P=0.40)$, the two groups did not differ significantly in terms of age.

In the suicide group, mean of starting age for alcohol consumption was $19.29 \pm 2.87$ and mean of starting age for substance use was $20.77 \pm 6.89$ and mean of starting age for smoking was $19 \pm 4.82$, but in the normal group, the mean of starting age for smoking was $35 \pm 7.07$. Suicidal patients 
Table 1. Descriptive statistics of demographic variables

\begin{tabular}{|c|c|c|c|c|c|c|c|}
\hline \multirow{2}{*}{ Variables } & & \multicolumn{2}{|c|}{ Suicide Group } & \multicolumn{2}{|c|}{ Normal Group } & \multicolumn{2}{|c|}{ Total } \\
\hline & & No. & Percent & No. & Percent & No. & Percent \\
\hline \multirow{2}{*}{ Sex } & Male & 27 & 35.1 & 44 & 57.1 & 71 & 46.1 \\
\hline & Female & 50 & 64.9 & 33 & 42.9 & 83 & 53.9 \\
\hline \multirow{5}{*}{ Education } & Middle school & 27 & 35.5 & 3 & 3.9 & 30 & 19.5 \\
\hline & Diploma & 33 & 43.4 & 27 & 35.1 & 60 & 39 \\
\hline & Associate degree & 2 & 2.6 & 5 & 6.5 & 7 & 4.5 \\
\hline & Bachelor & 11 & 14.5 & 32 & 41.6 & 43 & 27.9 \\
\hline & M. A and upper & 3 & 3.9 & 10 & 13 & 13 & 8.4 \\
\hline \multirow{5}{*}{ Marital Statues } & Single & 22 & 28.6 & 40 & 51.9 & 62 & 40.3 \\
\hline & Married & 40 & 51.9 & 31 & 40.3 & 71 & 46.1 \\
\hline & Separated & 3 & 3.9 & 0 & 0 & 3 & 1.9 \\
\hline & Divorced & 11 & 14.3 & 6 & 7.8 & 17 & 11 \\
\hline & Widow & 1 & 1.3 & 0 & 0 & 1 & 0.6 \\
\hline \multirow{3}{*}{ Occupation } & Employed & 24 & 31.2 & 69 & 89.6 & 93 & 60.4 \\
\hline & Unemployed & 28 & 36.4 & 7 & 9.1 & 35 & 22.7 \\
\hline & Housewife & 25 & 32.5 & 1 & 1.3 & 26 & 16.9 \\
\hline \multirow{2}{*}{ Housing } & Land lord & 50 & 64.9 & 63 & 81.8 & 113 & 73.4 \\
\hline & Tenant & 27 & 35.1 & 14 & 18.2 & 41 & 26.6 \\
\hline \multirow{3}{*}{ Income } & Weak & 34 & 44.2 & 5 & 6.5 & 39 & 25.3 \\
\hline & Average & 18 & 23.4 & 8 & 10.4 & 26 & 16.9 \\
\hline & Good & 25 & 32.5 & 64 & 83.1 & 89 & 57.8 \\
\hline \multirow{2}{*}{$\begin{array}{l}\text { Suicide attempt } \\
\text { history }\end{array}$} & Yes & 20 & 26 & 0 & 0 & 20 & 13 \\
\hline & No & 57 & 74 & 77 & 100 & 134 & 87 \\
\hline \multirow{2}{*}{ Self-injury history } & Yes & 20 & 26 & 0 & 0 & 20 & 13 \\
\hline & No & 57 & 74 & 77 & 100 & 134 & 87 \\
\hline \multirow{2}{*}{ Psychiatric history } & Yes & 45 & 58.4 & 6 & 7.8 & 51 & 33.1 \\
\hline & No & 32 & 41.6 & 71 & 92.2 & 103 & 66.9 \\
\hline \multirow{2}{*}{ Tattoo history } & Yes & 7 & 9.1 & 0 & 0 & 7 & 4.5 \\
\hline & No & 70 & 90.9 & 77 & 100 & 147 & 95.5 \\
\hline \multirow{2}{*}{$\begin{array}{l}\text { History of drug } \\
\text { use }\end{array}$} & Yes & 13 & 16.9 & 0 & 0 & 13 & 8.4 \\
\hline & No & 64 & 83.1 & 77 & 100 & 141 & 91.6 \\
\hline \multirow{2}{*}{$\begin{array}{l}\text { History of } \\
\text { smoking }\end{array}$} & Yes & 16 & 20.8 & 2 & 2.6 & 18 & 11.7 \\
\hline & No & 61 & 79.22 & 75 & 97.4 & 136 & 88.3 \\
\hline \multirow{2}{*}{$\begin{array}{l}\text { History of alcohol } \\
\text { consumption }\end{array}$} & Yes & 7 & 9.1 & 1 & 1.3 & 8 & 5.2 \\
\hline & No & 70 & 90.9 & 76 & 98.7 & 146 & 94.8 \\
\hline
\end{tabular}

started smoking at younger age than healthy counterparts. Based on GHQ, non-suicidal individuals had no specific problem in the general health scores and scales $(7.55 \pm 1.87)$.

To investigate the difference between TCI variables among general population and suicide attempters in terms of the normal distribution of data, Kolmogorov-Smirnov test was used, and then using the logarithmic method (Napier), the normalization of the variables was tested, which did not obtain the required parameters for $t$ test, and therefore they were analyzed through Mann-Whitney U test.

Table 3 shows the results of Mann-Whitney test for the TCI variables between the two groups.

In general, the data in Table 3 show that suicide attempters and non-suicidal individuals were significantly different in terms of TCI variables. The suicide attempters had significantly higher scores in NS and HA, while they exhibited lower scores in RD, P, CO, SD, and ST.

No significant difference existed in the suicide-attempting group in terms of gender (male $=27$, female $=50, \chi^{2}=6.87$, $\mathrm{df}=1, P=0.08)$.

Table 4 shows results of regression test (stepwise method) and models for predicting suicide attempt. These results show that the multiple correlation coefficients for the last model (3) could predict up to $65 \%$ of suicide attempts in suicidal individuals. The results $(\mathrm{F}(3,72)=46.38$, $P=0.000)$ also confirm the linearity of the model.

History of suicide attempts revealed the greatest contribution in predicting suicide attempts (beta $=0.54$, $P=0.000$ ). Starting age for alcohol consumption (beta $=$ 2.98, $P=0.000)$ and the history of alcohol consumption 
Table 2. The types of drug used for suicide

\begin{tabular}{lcc}
\hline Type of drug & No. & Percent \\
\hline No drug information & 17 & 22.1 \\
\hline Analgesics & 4 & 5.2 \\
\hline NSAIDs & 3 & 3.9 \\
\hline TCAs & 3 & 3.9 \\
\hline SSRIs & 1 & 1.3 \\
\hline Mood stabilizers & 2 & 2.6 \\
\hline Benzodiazepines & 19 & 24.7 \\
\hline Clonidine & 4 & 5.2 \\
\hline Tramadol & 5 & 6.5 \\
\hline Detergents & 4 & 5.2 \\
\hline Barbiturates & 2 & 2.6 \\
\hline miscellaneous & 5 & 6.5 \\
\hline Anti-psychotic agents & 1 & 1.3 \\
\hline Organophosphorus & 5 & 6.5 \\
\hline Rice tablet & 2 & 2.6 \\
\hline
\end{tabular}

(beta $=2.64, P=0.000$ ) contributed to predicting suicide attempts, subsequently.

\section{Discussion}

Based on the findings in this study, suicide attempters have higher scores on NS, HA and lower scores on RD, P, SD, CO and ST.

Sharif et al (15) have reported that individuals with suicidal thoughts and also suicide attempters have a higher score than healthy people in terms of neuroticism (hostility). Neuroticism can be considered as an equivalent for the NS in the Cloninger's inventory. Our results are in line with the study conducted by Sharif et al which revealed that suicide attempters had higher scores on NS.

Shakeri et al (2) demonstrated that neuroticism and introversion were prevalent among people with suicide attempts. Similarly, our results showed that the suicidal patients have higher scores in NS behavior.

According to recent findings $(11,12)$, high $\mathrm{HA}$ and $\mathrm{NS}$, along with low $\mathrm{RD}, \mathrm{SD}$ and $\mathrm{CO}$ are considered as components of temperament and character among suicide attempters. These findings are consistent with our results. In spite of having meaningful differences in NS and SD between suicide attempters and non-attempters, our study did not show significant predictive values for these factors (NS and SD had higher scores in the suicide attempters and normal people, respectively). Meanwhile, Arkar (10) revealed that high NS and low SD scales were the values that may predict suicide attempts; the findings which were not confirmed by the current research.

Unlike the present study, evidence shows that marital status is a predictive variable for suicide attempt, indicating that single individuals have a higher rate of suicide (16). Previous suicide attempts, the history of and starting age for alcohol consumption were revealed as the predictive variables for suicide attempts in our study.

Table 3. The mean of the Cloninger's Temperament and Character Inventory test variables

\begin{tabular}{lcccc}
\hline Variables & $\begin{array}{c}\text { Suicide Group } \\
\text { Ranks (Mean) }\end{array}$ & $\begin{array}{c}\text { Normal Group } \\
\text { Ranks (Mean) }\end{array}$ & Mann-Whitney & P value \\
\hline Novelty seeking & $6649.50(86.36)$ & $5285.50(68.64)$ & 2282.50 & 0.01 \\
\hline Harm avoidance & $8052(104.57)$ & $3883(50.43)$ & 880 & 0.000 \\
Reward dependence & $3899(50.64)$ & $8036(104.36)$ & 896 & 0.000 \\
\hline Persistence & $3524.50(45.77)$ & $8410.50(109.23)$ & 521.50 & 0.000 \\
Cooperativeness & $3463.50(44.98)$ & $8471.50(110.02)$ & 460.50 & 0.000 \\
Self-directedness & $3106(40.34)$ & $8829(114.66)$ & 103 & 0.000 \\
Self-transcendence & $5218(67.77)$ & $6717(87.23)$ & 2215 & 0.05 \\
\hline
\end{tabular}

Table 4. Results of regression test and models and standardized beta coefficients for predicting suicide attempt (criterion variable: suicide attempt)

\begin{tabular}{|c|c|c|c|c|c|c|c|c|c|c|}
\hline \multirow[t]{2}{*}{ Model } & \multirow[t]{2}{*}{ Variables } & \multirow[t]{2}{*}{$\mathbf{R}$} & \multirow[t]{2}{*}{$\mathbf{R}^{2}$} & \multirow{2}{*}{$\begin{array}{c}\text { Adjusted } \\
\mathbf{R}\end{array}$} & \multirow[t]{2}{*}{ SE } & \multicolumn{2}{|c|}{$\begin{array}{l}\text { Unstandardized } \\
\text { coefficients }\end{array}$} & \multirow{2}{*}{$\begin{array}{c}\begin{array}{c}\text { Standardized } \\
\text { coefficients }\end{array} \\
\text { Beta }\end{array}$} & \multirow[t]{2}{*}{$T$} & \multirow[t]{2}{*}{$P$ value } \\
\hline & & & & & & B & SE & & & \\
\hline 1 & History of suicide attempt & 0.62 & 0.38 & 0.37 & 0.97 & -1.74 & 0.25 & -0.062 & -6.76 & 0.000 \\
\hline \multirow{2}{*}{2} & History of suicide attempt & \multirow{2}{*}{0.71} & \multirow{2}{*}{0.51} & \multirow{2}{*}{0.49} & \multirow{2}{*}{0.87} & -1.59 & 0.23 & -0.57 & -6.83 & 0.000 \\
\hline & Starting age for alcohol consumption & & & & & 0.08 & 0.02 & 0.36 & 4.33 & 0.000 \\
\hline \multirow{3}{*}{3} & History of Suicide Attempt & \multirow[b]{2}{*}{0.81} & \multirow[b]{2}{*}{0.66} & \multirow[b]{2}{*}{0.65} & \multirow[b]{2}{*}{0.73} & -1.52 & 0.20 & -0.54 & -7.73 & 0.000 \\
\hline & Starting age for alcohol consumption & & & & & 0.65 & 0.10 & 2.98 & 6.36 & 0.000 \\
\hline & History of alcohol consumption & & & & & 11.13 & 1.97 & 2.64 & 5.65 & 0.000 \\
\hline
\end{tabular}

R: Regression; R²: R-squared; SE: standard error. 


\section{Limitations}

A relatively high drop-out rate and enrolling only selfpoisoning patients might be considered as the study limitations.

\section{Conclusion}

The role of temperament and character in suicide tendency is re-emphasized. The suicide-attempting people have higher scores than normal people in NS and $\mathrm{HA}$, and have lower scores in the scales, such as RD, P, CO, SD and ST. The suicide attempt history, the history and age of early alcohol start can predict the potential for re-attempting suicide. It is crucial for policy-makers to focus on interventions such as social life skills training and strengthening coping strategies to prevent impulsive behaviors, avoidance of drugs and alcohol consumption, creating a supportive environment, appropriate emotional drain, identifying the stimuli or situations that result in the feelings of despair or production of suicidal thoughts.

\section{Authors' contribution}

ARSK designed the project. SA and $\mathrm{EH}$ reviewed the literature and prepared the proposal. NS performed case finding and implemented the procedures. SS and MGJ analyzed the data. ARSK and EH wrote the manuscript. All read it and the first author finalized the paper.

\section{Ethical issues}

The study was approved by the ethics committee of Tabriz University of Medical Sciences (ethics No. TBZMED. REC.1394.266).

\section{Acknowledgment}

This paper has been extracted from an approved MD dissertation by Nima Sarihi with No.16/2-1-93. The authors would like to appreciate the great cooperation of the participants, as well as the staff of the Sina EducationalMedical hospital of Tabriz.

\section{References}

1. Fleischmann A, De Leo D. The World Health Organization's report on suicide: a fundamental step in worldwide suicide prevention. Crisis 2014; 35(5): 289-91. doi: 10.1027/02275910/a000293.

2. Shakeri J, Parvizifard AA, Sadeghi K, Moradi R. Personality Traits, Stress, Coping and Religious Attitudes among Individuals Attempting Suicide. Iranian Journal of Psychiatry and Clinical Psychology 2006; 12 (3): 244-50. [In Persian].

3. Hawton K, Linsell L, Adeniji T, Sariaslan A, Fazel S. Selfharm in prisons in England and Wales: an epidemiological study of prevalence, risk factors, clustering, and subsequent suicide. Lancet 2014; 383(9923): 1147-54. doi: 10.1016/ s0140-6736(13)62118-2.

4. Foster T, Gillespie K, McClelland R. Mental disorders and suicide in Northern Ireland. Br J Psychiatry 1997; 170: 44752. doi: 10.1192/bjp.170.5.447.

5. Camarena B, Fresán A, Sarmiento E. Exploring personality features in patients with affective disorders and history of suicide attempts: a comparative study with their parents and control subjects. Depress Res Treat 2014; 2014: 291802. doi: 10.1155/2014/291802.

6. Pienaar J, Rothmann S, van de Vijver FJR. Occupational stress, personality traits, coping strategies, and suicide ideation in the South African Police Service. Crim Justice Behav 2007; 34(2): 246-58. doi: 10.1177/0093854806288708.

7. Mihandoost Z. A meta-analysis of suicide rates in male and in female suicide in Iran. Educ Sci Psychol 2013; 26(4): 1221.

8. Cloninger CR, Przybeck TR, Svrakic DM, Wetzel RD. The Temperament and Character Inventory (TCI): A guide to its development and use. St. Louis, MO: Center for Psychobiology and Personality, Washington University; 1994.

9. Shafiee-Kandjani AR, Amiri S, Arfaie A, Ahmadi A, Farvareshi M. Relationship between personality profiles and suicide attempt via medicine poisoning among hospitalized patients: a case-control study. Int Sch Res Notices 2014; 2014: 675480. doi: 10.1155/2014/675480.

10. Arkar H. Relationship between Attempted Suicide and Cloninger's Personality Dimensions of Temperament and Character in Turkish Psychiatric Patients. New/Yeni Symposium Journal 2010: 48(2): 110-5.

11. Woo YS, Jun TY, Jeon YH, Song HR, Kim TS, Kim JB, et al. Relationship of temperament and character in remitted depressed patients with suicidal ideation and suicide attempts--results from the CRESCEND study. PLoS One 2014; 9(10): e105860. doi: 10.1371/journal.pone.0105860.

12. Seo HJ, Jung YE, Jeong S, Kim JB, Lee MS, Kim JM, et al. Personality traits associated with suicidal behaviors in patients with depression: the CRESCEND study. Compr Psychiatry 2014; 55(5): 1085-92. doi: 10.1016/j. comppsych.2014.03.014.

13. Kaviani H, Poor Naseh M. Validation of temperament and character inventory (TCI) in Iranian sample: normative data. Tehran University Medical Journal 2005: 63(2): 89-98. [In Persian].

14. Hooman A. Standardization of General Health Questionnaire (GHQ) among undergraduate students of Tarbiyat Moallem University. Tehran, Iran: Research Institute of Tarbiyat Moallem University; 1997. [In Persian].

15. Sharif F, Parsnia A, Mani A, Vosoghi M, Setoodeh G. Comparison of personality traits, coping styles, and psychiatric disorders in adult suicidal and non-suicidal individuals. Int J Community Based Nurs Midwifery 2014; 2(3): 148-56.

16. Kyung-Sook W, SangSoo S, Sangjin S, Young-Jeon S. Marital status integration and suicide: a meta-analysis and metaregression. Soc Sci Med 2018; 197: 116-26. doi: 10.1016/j. socscimed.2017.11.053. 